\title{
NUEVAS VICISITUDES DE LA POESÍA ESPAÑOLA A PARTIR DEL PERIODO TRANSICIONAL
}

\author{
Alejandro Simón Partal \\ Universidad de Ostrava \\ República Checa \\ jose.simon@osu.cz \\ Universidad de Zaragoza \\ España \\ simonpartal@unizar.es
}

doi.org/10.15452/SR.2021.21.0005

Resumen. Como todo proceso de cambio, la Transición española supuso una ruptura en la vida de la gente y en la manera en que las personas interpretaban la realidad. Esa travesía hacia otra forma de convivencia también se produjo en la poesía del momento, que pasó de la corriente culturalista predominante en la primera mitad de los años setenta, a la poética de la vida, de la calle, que acabó imponiéndose a principios de los años 80, y que se ha mantenido vigente hasta la poesía actual, en la que la política y la protesta han vuelto a ser la base de nuevas poéticas. Aquella generación surgida en los 80 tras la instauración de la democracia defendía una poesía más diáfana, unos versos que atendieran a la gente, que hablase el lenguaje de la calle. En este estudio pretendemos abordar ese proceso de cambio y cómo ese nuevo realismo va a ramificarse en distintas tendencias que amparan y atienden a las distintas relaciones del hombre con la naturaleza, con las afueras, que no van a dejar de cuestionar la libertad y las limitaciones humanas desde entonces hasta nuestros días.

Palabras clave. Poesía española. Transición. Democracia. Literatura. Realismo. Culturalismo.

Abstract. New Vicissitudes of Spanish Poetry from the Transitional Period. Like any process of change, the Spanish Transition meant a break in people's lives and in the way that people interpret reality. This change occurred in the recent poetry too, which went from the predominant culturalist current in the first half of the seventies, to the poetics of life, of the street, which ended up imposing itself in the early 80's, and it has remained till current poetry, 
in which politics and protest have once again become the basis of new poetics. The generation that emerged in the eighties after the establishment of democracy defended a more transparent poetry, that spoke the language of the street. This study focuses on this process of change and on how the new realism will branch out into different trends, that protect and attend to the different relationships between man and nature, with the outskirts, which will not stop questioning freedom and human limitations since then until today.

Keywords. Spanish poetry. Transition. Democracy. Literature. Realism. Culturalism. 


\section{Contexto lírico de un proceso democrático}

En una entrevista publicada en The Paris Review y recogida recientemente por la editorial Acantilado, la escritora Margarite Yourcenar comentaba que lo sagrado es la esencia misma de la vida. Y, por tanto, «es fundamental tener conciencia de lo sagrado en todo momento, incluso ahora, mientras sostengo este vaso en la mano» (The Paris Review, 2020: 2245). Los hechos más cotidianos, el vaso de agua fría, un valle sobre el que cae la tarde, esconden los milagros cercanos de nuestra existencia. Vivir es un misterio. $\mathrm{Y}$ a ese misterio la poesía y la literatura añaden secretos o trazan lindes para contenerlo. Apuntaba John Updike que los libros han de tener secretos, igual que las personas. Y desde ese velo se suele ofrecer caminos más amplios, caminos que engendran vida desde la propia vida. El filósofo Josep María Esquirol apunta en ese extremo:

El problema es susceptible de resolución; el misterio no. El problema es objetivo, es decir, lo tenemos delante; el misterio nos aplaca y nos implica: estamos en él. El problema exige ingenio para su resolución (desde cómo hacer fuego a cómo instalarnos en Marte); el misterio reclama atención y respeto. El tiempo, la vida humana, la presencia del otro, tienen que ver con el misterio. Los sentimientos más fuertes de nuestra vida son los relativos al misterio. Cuando se anula o se ignora, mengua la vida (Esquirol, 2018: 13-14).

Y lo cierto es que la negación de ese misterio en determinadas corrientes poéticas que brotaron a partir de la Transición española ha empobrecido el fin último del género, que es aprender a mirar más allá de lo evidente, y, a partir de ahí, ser capaces de una vida que transcienda.

Las circunstancias políticas y culturales que se dieron en España a partir de 1975 van a tener una repercusión directa en la poesía del momento y en la que sucederá en las siguientes décadas y generaciones. Esa transformación va a dar lugar a un profundo cambio de la realidad y de cómo esta se percibe. La Transición y la incertidumbre de los primeros años de la democracia, la convulsión de las nuevas conductas y roles sociales durante los años ochenta -con la entrada en la OTAN y el fin de la Guerra Fría- van a tener una repercusión directa en la poesía, que parte, como casi todo, de la experiencia. Ello derivó en distintas mutaciones del discurso teórico y, posteriormente, en una revisión de la Transición y de la democracia, que traerá la ebullición de nuevas voces y categorías críticas que evocan este periodo desde una heterodoxia que, en el dominio poético, parte de una reformulación esencial desde 1989 y que vincula poesía y compromiso sociopolítico. Poesía urbana, desencanto, estereotipos en las representaciones del cambio democrático, realismo sucio vs. realismo epicúreo; a partir de estos extremos vitales podemos reconstruir no solo la revisión de dichos periodos, sino entender hacia dónde va la transformación social buscada y las nuevas identidades en el tercer milenio, momento en el que se produce una nueva recuperación de cuestiones relacionadas con el compromiso, la poesía social, el desencanto y la revisión de la democracia a partir de las reivindicaciones feministas y de identidad sexual, que ha llevado al país a una situación social y política completamente distinta en esta segunda década del siglo XXI, pero repitiendo errores que condujeron a esta situación. 
A mediados de los años 90 surgirá un nuevo realismo de carácter epicúreo, con una marcada voluntad de elevación estética y un tono helenístico de búsqueda de la felicidad y del buen vivir. Implicaba un compromiso desde una perspectiva distinta, que revisaba la experiencia desde otro ángulo y que podía entenderse como una salida a ese descontento social. Esta recuperación del compromiso en la poesía española no se va a limitar a los años ochenta y noventa, sino que continúa en autores jóvenes nacidos en esas décadas y que conforman en la actualidad unas voces que cuestionan nuestra memoria última desde el desengaño o la militancia, como muestran los casos de los poetas Antonio Lucas o Elena Medel. Esta última es además autora de Las maravillas, novela en la que aborda algunas de las cuestiones mencionadas, como el desencanto juvenil y la precariedad laboral en determinados sectores de la sociedad. Como poeta, Medel obtuvo el Premio Loewe con su libro Chatterton, título que formó parte del volumen que recoge toda su poesía, titulado Un día negro en una casa de mentira (1998-2014), en el que aborda los temas que más adelante seguiría desarrollando en la novela: feminismo, desamor e incertidumbres: «Yo he pensado en nosotras. / No sé si sabes a lo que me refiero. Te estoy hablando del fracaso» (Medel, 2014: 201).

Esa frustración social va a impulsar una poesía más amplia, más despojada, que ahonda en lo social sin discriminar aspectos más experimentales. Como ha señalado Antonio Orihuela:

1975 iba a suponer para las prácticas experimentales un gran año gracias a la antología La escritura en libertad que Fernando Millán y Jesús García Sánchez acababan de editar en Alianza Tres sobre la poesía experimental. Lejos ya de las intenciones programáticas inaugurales, en su prólogo, los autores abogan por la intención totalizadora de la poesía y su capacidad para integrar otros géneros. (...) Entre 1976 y 1982 nos encontramos ante la expansión y relativa normalización de las propuestas visuales-experimentales en España. Madrid, centro neurálgico de la actividad poético experimental de los primeros años setenta cede su lugar a la periferia, donde las conferencias, artículos en revistas, periódicos y exposiciones se multiplican (Orihuela, 2013: 42).

1977 fue un año significativo para toda la sociedad española, que ejercía su derecho al voto en unas elecciones democráticas por primera vez en cuarenta años. Durante ese año se vislumbró el fin de la censura, nació el Ministerio de Cultura y el poeta Vicente Aleixandre recibió el Premio Nobel de Literatura. Fue un año importante para una generación nacida entre 1954 y 1968, heredera de la ideología de la generación del 68, a la que Carlos Bousoño denominó como «generación marginada» (Lanz, 2007: 72). Todavía en 1977 se asentaba en buena parte de la juventud española una tradición ideológica y cultural de fundamento marxista radical, que muchas veces lindaba con el anarquismo.

El periodo histórico que discurre entre 1979 y 1982 se caracteriza por un impulso de ruptura radical, un tiempo nuevo donde el empoderamiento estaba en auge, y ciertas actitudes como la denuncia, la transgresión, la iconografía pop, el culto a lo popular, la cultura urbana, las drogas o la ambigüedad sexual van a ser valores que se van a mantener en esta revisión que se produce de la Transición española. Valores que ya puso en órbita Jaime Chávarri en su película sobre la familia Panero, titulada El desencanto, familia que va a seguir protagonizando este extremo, principalmente uno de los vástagos, Leopoldo María, que acabó sus días en un sanatorio de 
Las Palmas de Gran Canaria. Ese desencanto al que Chávarri puso caras en un espacio se ha mantenido constante en la poesía española hasta nuestros días. La literatura puede ser un atajo para la protesta, pero la protesta prefiere los hechos al lenguaje, porque el lenguaje, y, por ende, la palabra, requieren de un ritmo lento, de una serenidad que la multitud no abriga. Por contradictorio que suene, el lenguaje de la protesta se asemeja al lenguaje económico. Ese lenguaje de la calle que busca el rédito, la solución inmediata, entró de lleno en el poema, dejando a Dios sin espacio, y como apuntaba el Maestro Eckhart, sin Dios, el hombre no sabe qué hace (Pau, 2020: 58). Dios empezó a ser sospechoso en nuestra literatura, cuando no vilipendiado, lo que supuso empobrecimiento, a pesar de la reivindicación espiritual y religiosa de autores indiscutibles como María Zambrano, Ernesto Cardenal, Muñoz Rojas o María Victora Atencia. Oportuno es recuperar aquí las palabras del monje benedictino Lluis Duch:

Dios se torna superfluo porque el capitalismo como religión, como sucedáneo del paraíso reencontrado, ofrece sin cesar equivalentes funcionales de la providencia de Dios. Tiene, sin embargo, el inconveniente de que no habla el lenguaje del amor, que es o puede ser el que los seres humanos y Dios comparten, sino exclusivamente el lenguaje económico (Duch, 2017: 41).

La Transición como generadora de literatura negó a Dios, y bendijo el asfalto y la cerveza. Devolvió al macho ibérico todos sus clichés. Así lo entona el poeta y periodista Sergio C. Fanjul en su poema titulado, claro, «El desencanto», que forma parte de su libro Pertinaz freelance: «Los ochenta: mi padre borrado / desplomándose con gran estruendo / sobre el asfalto húmedo» (Fanjul, 2016, 34).

Esta orientación poética arranca con el impulso que supuso la aparición a mediados de los años sesenta de una serie de libros de poetas jóvenes que empezaron a planear una renovación estética, poemarios como Arde el mar (1966), de Pere Gimferrer, o Dibujo de la muerte (1966), de Guillermo Carnero, abrieron nuevas formas de elevar el poema sobre nuestra realidad. Comenzó a darse en esas décadas un neoesteticismo consolidado tras la publicación de la famosa antología de Castellet, Nueve novísimos poetas españoles. En un texto titulado «Poética», recogido en la edición de José Luis García Martín titulada 30 años de poesía española, Gimferrer escribe: «La mayoría de los poetas españoles han hecho un arte de no decir absolutamente nada, ni respecto a la realidad ni respecto al lenguaje. Urge un planteamiento de la realidad. O mejor dicho: urge un planteamiento poético de la realidad» (García Martín, 2016: 57).

\section{La bifurcación estética de los años $\mathbf{8 0}$}

Apunta Juan José Lanz que, a partir de 1982, las diversas tendencias poéticas amalgamadas durante el lustro anterior comienzan a polarizar sus fuerzas en dos grupos antagónicos. La concesión del Adonais a El jardín extranjero, de García Montero, y de un accésit a Ludia, de Amparo Amorós, apuntaba las dos tendencias hegemónicas en la nueva poesía española, que acabarían consagrándose como «La otra sentimentalidad» $\mathrm{y}$ «La retórica del silencio». Con el fin de abarcar las diferentes tendencias que conviven en cada una de estas corrientes puede hablarse de una poesía del diálogo, como manifestaciones fundamentales de un espacio 
estético más transversal: la poética posmoderna. La posmodernidad va a abrir las distintas percepciones de la realidad de las que habló o a las que segregó, por ejemplo, Luis Bagué Quílez con los distintos tipos de realismo que conformarán la poesía española desde finales del siglo XX y principios del XXI, recogidos en el volumen Quien lo probó lo sabe: 36 poetas para el tercer milenio. A la posmodernidad, como periodo contiguo a la modernidad, solo le cabe reflexionar e inventariar sobre los logros conseguidos por aquella. Lo característico de la posmodernidad será la búsqueda de la disolución de la personalidad en los otros, la anulación completa de la conciencia individual, y esto va a convivir en una época, en un periodo histórico donde al poeta se le exige posicionamiento, ideología, conciencia.

La poesía de la experiencia es una de las etiquetas que más discusiones, debates, congresos -y casi asesinatos- ha suscitado, y sigue suscitando, en el reducido pero encendido ámbito de la poesía española contemporánea. Dicha expresión aparece por primera vez en España en el texto de Jaime Gil de Biedma Sensibilidad infantil, mentalidad adulta, publicado en 1959. En este texto, el poeta barcelonés proclama el magisterio exhibido por Robert Langbaum en su obra sobre la lírica inglesa, La poesía de la experiencia: el monólogo dramático en la tradición literaria moderna, publicada originariamente en 1957. La raíz de este desafuero al referirse a la poesía de la experiencia debe quizás buscarse en los orígenes del nuevo grupo poético que ve la luz en Granada en 1983, cuando Javier Egea, García Montero y Álvaro Salvador publican ese mismo año un manifiesto titulado La otra sentimentalidad y que, partiendo de la nueva sentimentalidad machadiana, trata de explicar la relación del hombre con el mundo en un momento histórico. El poeta Jorge Riechmann, por ejemplo, definió esa poesía como un cajón de sastre en el que se viene amontonando durante las dos últimas décadas toda poesía que presente ecos biográficos, intimistas, cotidianos, y que de manera consciente o inconsciente practica una política de exclusión hacia otras estéticas. Y desde entonces la reconciliación ha sido inviable.

En definitiva, el poeta en el acto de creación no solo dialoga con los elementos de su tradición cultural, sino que también lo hace con su propia experiencia, despersonalizándola, objetivándola y formulándola en términos de lenguaje, única forma de que esta se integre en el poema. De esta manera, la memoria, y su aplicación al momento actual, aspecto que aquí nos interesa, adquiere un relieve especial.

\section{La poesía joven de los $\mathbf{9 0}$ ante el periodo transicional}

A finales de los años 80 y principios de los 90 se empieza a percibir un cambio de rumbo general dentro de la poesía más joven. En 1995 apareció una nueva antología realizada por José Luis García Martín: Selección nacional. Última poesía española, donde el antólogo distingue dos maneras de entender el quehacer poético: la que él ha denominado como «poesía figurativa» y la «poesía del silencio» o del «lenguaje». Juan José Lanz indica en su estudio Nuevos y novísimos poetas que la voz del antólogo colapsa o silencia a la de los autores seleccionados y, por consiguiente, algo funciona mal.

Los antólogos y quienes creen en las antologías vienen mostrando una fe inquebrantable en que la historia de la literatura es un organismo vivo que evoluciona y se transforma cada cuatro o cinco 
años. De esta forma resulta más perceptible el deseo de intervención de los antólogos que la reflexión o interpretación de acontecimientos literarios significativos. Otras veces ha prevalecido un afán de recuento, que suele resultar tan generoso como poco clarificador (Naval, 2010: 19).

Vinieron más antologías, en efecto, como la que en 1996 publica Miguel García-Posada, quien enfatiza una serie de factores que caracterizan la producción poética desde la Transición: poesía urbana, tendencia a la ficcionalización del yo poético, poesía narrativa, tematización del desencanto, formalismo métrico, tendencia a la relectura de la tradición en forma de imitación, retorno a los temas realistas. Después vendrán más antologías de García Martín, como la publicada en 1996 Treinta años de poesía española (1965-1999), y la respuesta de Villena con 10 menos 30 (1997), en esa batalla que mantienen abierta desde hace ya unos años.

Ese realismo tan trabajado y cultivado en los ochenta ha mutado en distintas vertientes que Bagué Quílez ramifica de la siguiente forma: un realismo singular (Luis García Montero), un realismo entrometido (Fernando Beltrán), un realismo de indagación (Jorge Riechmann), un realismo sucio, que aborda el desencanto transicional (Roger Wolfe), y un realismo limpio (Karmelo C. Iribarren) (Bagué, 2012: 23). Existe una tradición crítica, como ha estudiado Juan José Lanz, que revisa el periodo transicional como un proceso no culminado. En este sentido, el primer ensayo destacable es el de Gerard Imbert, Los discursos del cambio. Imágenes e imaginarios sociales en la España de la Transición (1976-1982), publicado por la editorial Akal, donde por primera vez se cuestiona la verdad del relato de la Transición. También los trabajos de Alberto Medina -Exorcismos de la memoria: políticas y poéticas de la melancolía en la Transición Española (Libertarias Prodhufi, 2001)- y Cristina Moreiras -Cultura herida. Literatura y cine en la España democrática (Libertarias Prodhufi, 2002)-. Respecto al realismo sucio, Roger Wolfe va a ser uno de los poetas más insistentes en la representación del desencanto, un desencanto que se concreta en las manifestaciones organizadas en Madrid el 15 de mayo de 2011 (15M). En este contexto convulso, pequeñas editoriales interesadas nuevamente por la poesía política y social, como la editorial Séneca, han publicado antologías plagadas de aforismos (normalmente panfletarios), que si bien no tienen altura literaria («manos arriba esto es un contrato», por ejemplo), son síntomas sin duda de un reencuentro de la poesía con la protesta y la política. «Democracia me gustas porque estás como ausente», podía leerse en una de las pancartas. La poeta madrileña Almudena Guzmán recoge esta nueva realidad en su libro Zonas comunes, donde ya en el primer poema apunta con ironía: «Manifestación de leprosos, no autorizada, en la Gran Vía. Las fuerzas antidisturbios de Mesala / han acordonado la zona. / Ni rastro de Charlton Heston» (Guzmán, 2011: 9).

Otro autor que sumó su voz a estas formas de denuncia fue Antonio Lucas, poeta y periodista que llegó a su madurez literaria con Los desengaños (Visor, 2014), libro que disecciona el momento y el país en el que vive mostrando las insatisfacciones de su tiempo y de su espacio, a través de una revolución tranquila, más sosegada. El poemario aborda desde el mismo título el sentir de toda una generación, la nacida a mediados de los setenta, a la que el autor pertenece: «Dónde los gritos, los abrazos, las caducas consignas, la imposible soberbia de las revoluciones» (Lucas, 2014: 29). 
La poeta Erika Martínez, por su parte, invita a una reflexión en torno al poder y al escaso margen de maniobra que nos permite:

\author{
Depositamos artículos prohibidos \\ en una caja transparente: \\ tijeras, cuchillas, mecheros \\ inútiles como sobres de votación. \\ Dos agentes custodian \\ la ficción del Estado \\ (Martínez, 2013: 31).
}

Destaca también Juan Manuel Villalba, que recurre a la denuncia, al hartazgo y a la desmemoria en un libro que tituló, cómo no, Indignación: «Los sueños que se fueron, los perdidos, los que acabaron en cunetas, los que nunca supieron ser soñados» (Villalba, 2002: 16). Por el mismo camino avanza el poeta Antonio Jiménez Millán, catedrático de Literaturas Románicas en la Universidad de Málaga, que en su libro Veinte sátiras y un deseo (2014-2018) se apoya en la tradición satírica que se remonta a los clásicos griegos y latinos, y cuyos textos fueron escritos, como puede leerse en la contracubierta del libro, «durante uno de los episodios más negros de la democracia española», episodio que, según el autor, responde a la gestión política del Partido Popular. En uno de los poemas puede leerse: «Ay, qué gente palurda. / Que dejen ya su silla, / que pillen una cuerda / y que se acabe ya la pesadilla» (Jiménez, 2018: 33). Esa desazón política suele venir acompañada de un descalabro emocional que cierra el círculo de esa querencia urbana por recorrer todos los barrizales del hombre. Así ocurre en el caso de Jordi Virallonga, que ha enfocado parte de esa obra como gesto de rebeldía contra el poder y sus abusos, como defensa de la pasión frente al cinismo: «He comprado un whisky doce años / y esta noche seré cuando, como y donde quieras. / Quizás seas la más puta de todas, / pero no dejaré que te mueras» (Virallonga, 2010: 33).

Cuando la realidad no se concreta en los caminos esperados, los deseados, los sueños se transforman en ancla y destino. Una de las poetas más notables, autora del año en Andalucía en 2017, es Julia Uceda, que vivió un exilio voluntario, elegido, sin por ello librarse del todo de esa carga que arrastran los que, de una u otra forma, se marchan. Poesía y filosofía se vuelven a unir en la poesía de Uceda desde su problemática social y existencial, que quedan integradas en su obra. Una poesía que se hace esencialmente humana. Memoria, recuerdo y acción de recordar no son tema, sino germen de pensamiento y pensamiento mismo, creación poemática. Sus libros, fuera de los cauces de la poesía social al uso, están impregnados de una intensa y ávida conciencia que no parte de la denuncia sin adoctrinamientos, sino desde una retórica muy parecida, p. ej., a la de María Zambrano: palabras sencillas desde las que no se siente libre de enseñarle a nadie lo que importa. Una poesía social que coincide con esa visión híbrida entre la denuncia mundana, un escepticismo radical y una espiritualidad perpleja, que linda con la mística y desde esa elevación reconstruye nuestro presente, lo salva de más alteridades. Julia Uceda emigró no porque la persiguieran, sino porque necesitaba salir, conocer otros silencios: 
«No me llames extranjero / Van diciendo por los siglos / Sucesivos españoles / A españoles sucesivos» (Uceda, 2010, 46).

\section{Conclusiones}

Escribe el poeta cordobés Pablo García Casado: «Media España quiere volver a cerrar los párpados, volver a dormir, descansar hasta bien entrada la mañana, pero es demasiado tarde, y ya han repartido los periódicos» (García Casado, 2015: 36). A lo que añade el autor sevillano Braulio Ortiz Poole: «España, país de tanta luz, ¿por qué esta voluntad hacia la tiniebla?» (Ortiz, 2020, 55). España nunca ha dejado de ser una preocupación. Lo fue para Luis Cernuda, que se sentía un español sin ganas, y así ha continuado, ya sea desde la reivindicación, la denuncia o los complejos más personales.

Hemos comprobado cómo la poesía española no ha dejado de entender la realidad política como destino de sus poemas, a pesar de que ese destino suele llevar por los peores caminos del género, por las peores evidencias del lenguaje. Ha quedado demostrado que la protesta y el poema difícilmente pueden dar un resultado alejado del dogmatismo, que es la muerte del verso al convertirlo en eslogan. El poeta no debe imponer, sino proponer, y en ese diálogo la realidad cultural y política no ha dejado de ocupar un espacio considerable. La poesía social y urbana, que ha vivido horas bajas en las últimas décadas, vuelve a pedir su lugar en el poema, para así reconstruir una generación, unas voces que aborden los nuevos desafíos de nuestro tiempo y sigan recomponiendo o desgastando la noción de país. Mientras la narrativa, la prensa o el cine cuentan historias y miran al pasado, la poesía señala, dirige su mirada al futuro, a lo que aún no conocemos, como ocurre con lo misterioso, como lo que nos conforma desde lo más esencial. El nuevo escenario acaecido tras los movimientos populares que comenzaron en la Puerta del Sol de Madrid y que cambiaron el tablero político, ha tenido su traducción en la poesía, que no es más que una posibilidad que tiene el hombre para hacer de la realidad algo que tenga que ver más con el presente que con el presentismo. La poesía que permanece, esa que atiende a lo sagrado y a la elevación humana y estética, recuerda que la única revolución posible está en el cuidado al otro, para así hacer de la historia que vendrá un lugar donde la verdad no se alimente de la perversidad, donde la vida importe más que la actualidad.

\section{Agradecimientos}

El artículo es fruto del proyecto de investigación Posílení vědeckých kapacit na OU II / Strengthening the university's scientific capacities II, OP VVV, reg. no. CZ.02.2.69/0.0/0.0/18_053/0017856 llevado a cabo en el Departamento de Estudios Románicos de la Facultad de Filosofía y Letras de la Universidad de Ostrava.

\section{Bibliografía}

\ BAGUÉ QUÍLEZ, Luis (2012). Quien lo probó lo sabe. 36 poetas para el tercer milenio. Zaragoza: Institución Fernando el Católico (Letra Última).

У DUCH, Lluis (2018). El exilio de Dios. Barcelona: Fragmentos.

\ ESQUIROL, Josep María (2018). La penúltima bondad. Barcelona: Acantilado. 
$\checkmark$ FANJUL, Sergio C. (2016). Pertinaz freelance. Madrid: Visor.

$\checkmark$ GARCía CASADO, Pablo (2015). García. Madrid: Visor.

У GARCía MARTín, José Luis (ed.) (2016). Treinta años de poesía española. Granada: Comares.

$\checkmark$ GUZMÁN, Almudena (2011). Zonas comunes. Madrid: Visor.

У JIMÉNEZ MILlA, Antonio (2018). Veinte sátiras y un deseo (2014-2018). Málaga: Litoral.

У LANZ, Juan José (2007). La poesía durante la Transición y la generación de la democracia. Madrid: Devenir.

$\checkmark$ LUCAS, Antonio (2014). Los desengaños. Madrid: Visor.

У MARTínez, Erika (2013). El falso techo. Valencia: Pre-Textos.

$\checkmark$ MEDEL, Elena (2014). Un día negro en una casa de mentira (1998-2014). Madrid: Visor.

У NAVAL, María Ángeles (2010). Poesía española posmoderna. Madrid: Visor.

У ORIHUEla, Antonio (2013). Poesía, pop y contracultura en España. Córdoba: Editorial Berenice.

$\checkmark$ ORTIZ POOLE, Braulio (2020). Gente que busca su bandera. Sevilla: Maclein y Parker.

$\checkmark$ PAU, Antonio (2020). Herejes. Madrid: Trotta.

$\checkmark$ THE PARIS REVIEW. Entrevistas (1953-2012). Barcelona: Acantilado.

$\checkmark$ UCEDA, Julia (2010). Hablando con un haya. Valencia: Pre-Textos.

У VILlalba, Juan Manuel (2002). Indignación. Valencia: Pre-Textos.

$\checkmark$ VIRALLONGA, Jordi (2010). Hace triste. Barcelona: DVD.

\author{
Alejandro Simón Partal \\ Katedra romanistiky \\ Filozofická fakulta \\ Ostravská univerzita \\ Reální 5 \\ 70103 OSTRAVA \\ República Checa
}

